Jurnal Evaluasi dan Pembelajaran

Volume 3 Nomor 1, Tahun 2021

Available online at https://jepjurnal.stkipalitb.ac.id/index.php/hepi

\title{
IMPLEMENTASI NILAI PANCASILA PADA GENERASI MILENIAL DI ERA SERBA MODERN
}

\author{
Angel Dwi Septianingrum ${ }^{1 *}$, Dini Anggraeni Dewi ${ }^{1}$ \\ 1Pendidikan Pancasila Universitas Pendidikan Indonesia \\ Jl. Pendidikan No.15, Cibiru Wetan, Cileunyi, Bandung, Jawa Barat 40625. \\ *Corresponding Author: Angelds@upi.edu /Diniangraenidewi@upi.edu
}

\begin{abstract}
Abstrak:
Dengan diadakannya penelitian ini maka, sejalan dengan mulai lunturnya nilai-nilai implementasi pancasila di era tang serba modern ini. Dapat dilihat dari beberapa perilaku masyrrakat yang cenderung hidup individu dan fokunya hanya ke ponsel pintar yang terus berkembang teknologinya. Hal-hal seperti ini tentunya akan akan semakin membuang jauh isi dari nilai pancasila yang sudah ada sejak dahulu sekali. Untuk itu perlu diadakan cara atau upaya untuk mengubah perilaku tersebut. Penelitian ini menggunakan sebuah metode yaitu kualitatif, dengan mengaji beberapa sumber yang sudah ada seperti buku, jurnal ataupun artikel. Penelitian ini ada untuk memperoleh sebuah upaya atau cara untuk mewujudkan implementasi pancasila pada generasi milenial di era yang serba modern ini. Pancasila merupakan senuah dasar Negara dimana kita harus perpedoman kepada setiap nilai yang ada
\end{abstract}

Kata kunci: Implementasi pancasila, Generasi Milenial, Nilai Pancasila.

\section{Abstract:}

With the holding of this research, it is in line with the fading of the values of Pancasila implementation in this modern era. It can be seen from some of the behavior of the people who tend to live individually and their focus is only on smart phones whose technology continues to develop. Things like this will certainly throw away the contents of the Pancasila values that have existed for a long time. For this reason, it is necessary to make means or efforts to change this behavior. This research uses a qualitative method, by examining several existing sources such as books, journals or articles. This research is there to obtain an effort or way to realize the implementation of Pancasila in the millennial generation in this modern era. Pancasila is the foundation of the State where we must be guided by all existing values.

Key words: Pancasila implementation, Millennial Generation, Pancasila Value

\section{Pendahuluan}

Sebagai seorang warga Negara yang baik, kita harusnya mengetahui bahwa pancasila adalah Ideologi Negara Indonesia. Pancasila digunakan sebagai asas Negara yang digunakan dalam pemerintahan serta mengutamakan seluruh komponen yang ada di wilayah Indonesia. Secara tata bahasa (etimologis), kata 'Pancasila" berasal dari bahasa sanskerta yaitu "panca" 
Jurnal Evaluasi dan Pembelajaran, 3 (1), Maret 2021 - 29

Angel Dwi Septianingrum, Dini Anggraeni Dewi

yang bermakna "lima" dan "sila" yang bermakna "dasar". Jadi dapat di simpulkan bahwasanya arti pancasila adalah "Lima Dasar".

Menurut Anggraini (2018), nilai-nilai pancasila dalam diri bangsa Indonesia mulai luntur seiring dengan berjalannya waktu. Jika dilihat dari contoh kecil, pada konsep nilai sila ke-3 yang mengajarkan adanya nilai persatuan, tapi di lunturkan dengan sikap individual karena makin berkembangnya teknologi. Yang saat ini berpotensi menjadi sebab perubahan sikap dari bangsa Indonesia adalah berkembangnya IPTEK yang semakin modern di Indonesia.

Perkembangnyya juga tidak lepas dari luhur nilai budaya dan agama, dimana itu juga terdapat moral bangsa. Saat ini budaya luar mulai masuk dan menyebar luas dalam masyarakat, sehingga banyak macam pengaruhnya mulai masuk ke segi internal maupun eksternal ke dalam diri bangsa Indonesia. Dari adanya Pancasila sebagai ideologi diharapakan mampu memperteguh sikap serta sifat masyarakat dalammenerima hal-hal diluar batas norma yang ada di Indonesia (Taufik, 2018).

Pancasila merupakan landasan dari segala sesuatu yang dilakukan bangsa dan dijadikan ideologi bagi bangsa Indonesia. Pancasila juga menjadi pemersatu bangsa yang sudah jelas beraneka ragam suku,ras,bahasa,agama dari sabang hingga merauke. Istilah pada pancasila sudah dikenal dari masa kerajaan sriwijaya dan majapahit yang dimana aspek nilai-nilainya sudah dikenal pada diterapkan pada masyarakatnya maupun pada kerajaannya, meskipun pada saat itu belum dirumuskan dengan konkrit. (Darmawan:2018)

Nilai serta sila yang terdapat dalam pancasila mempunyai paham untuk warga negaranya untuk terus mengingat isinya, selalu menerapkan dalam kehidupan, dan akan dibawa terus hingga akhir. Adapun tiga nilai didalam ideologi pancasila yaitu nilai dasar, nilai instrumental, dan nilai prakis (Agus:2016). Nilai dasar, ialah sesuatu yang sifatnya abstrak dan juga tetap, serta juga terlepas dari pengaruh perubahan dalam waktu. Nilai dasar berprinsip absrak juga dengan sifatnya yang umum, tidak terikat oleh waktu dan juga tempat.. Nilai Intrumental, ialah nilai yang bersifat kontekstual. Nilai instrumental adalah sebuah jabaran dari pancasila, yang juga merupakan arah kinerja dalan kurun waktu dan kondisi tertentu. Pada kandungan nilainya, nilai instrumental ialah kebijakan, strategi, organisasi, rencana, dan program, serta proyek yang dapat menindaklanjuti nilai dasar. Adapun lembaga yang mneyusun nilai instrumental yaitu MPR, Presiden, dan DPR. Yang terakhir ada nilai Praksis ialah nilai yang terdapat pada kehidupan sehari-hati.

Beberapa studi pernah dilakukan oleh Damanhuri, et al (2016) yang meneliti perkampungan Pancasila yang menerapkan nilai-nilai Pancasila sebagai upaya pembentukan karakter bangsa. Meski demikian, dalam implementasinya penerapan nilainilai Pancasila masih belum banyak mendapat dukungan dari masyarakat termasuk kesadaran akan perilaku yang mencerminkan nilai-nilai Pancasila sebagai penguatan karakter bangsa. Bahkan penelitian tersebut mendorong adanya dukungan dari berbagai pihak yang berwenang di dalamnya untuk lebih menerapkan nilai-nilai Pancasila dalam semua sendi kehidupan.

Oleh sebab itu upaya menumbuhkan sikap diri berdasarkan pancasila harusnya di terapkan sejak diri. Baik lingkungan keluarga ataupun sekolah harus tetap jadi pendukung untuk menumbuhkan sikap pancasila. Hal mudah yang dapat dilakukan seperti contoh sikap tolong menolong harus dibiasakan atau saling menyapa ketika bertemu orang lain. Hal-hal seperti itu kedepannya akan terus berdampak di masa depan.

Pendidikan pancasila sudah sepatutnya diajarkan kepada msayarakat umum yang hidup di zaman ini. Banyak individu yang yang masih kurang bisa menerapkan nilai-nilai pancasila pada kehidupannya.Banyak yang tidak bisa menerapkan menerapkan dalam kehidupan karena sudah tercampur dengan budaya-budaya barat yang serba instan. Jiwa 
sosialnya antar satu sama lainjuga kian luntur serta lebih mementingkan kehidupannya di dunia maya (Yudistira, 2016).

Dari sekian banyak generasi, generasi yang harus banyak ditanamkan nilai pancasilanya adalah generasi milenial dan juga generasi setelahnya, karena generasi itu ada beriringan dengan berkembangnya IPTEK. Banyak ahli juga menyatakan bahwasanya generasi milenial ini lebih mementingkan kehidupan sosial medianya dari pada menanamkan nilai pancasila dalam kehidupan sehari-harinya Sifat individunya juga menjadi-jadi atau kurang bersosialisasi terhadap lingkungan sekitar juga.

Lalu bagaimana caranya menyikapi generasi milenial ini yang $85 \%$ hidupnya menggunakan teknologi. Cara serta upaya yang paling efektif untuk menanamkan nilai pancasila pada zaman ini adalah dengan kesadaran diri setiap masing-masing. Apabila ada kemauan dalam dirinya maka nilai pancasila itu akan otomatis tertanam dalam dirinya.

Dengan adanya permasalah tersebut, penulis mendapatkan suatu rumusan masalah mengenai bagaimana nilai pancasila bisa tertanam pada generasi milenial di era yang serba modern ini serta upaya-upaya untuk meningkatkan kesadaran diri bahwasanya ideologi Negara kita adalah pancasila.

\section{Metode}

Dalam penelitian kali ini menggunakan analisis atau metode kualitatif, ialah sebuah penelitian yang teori atau pembahasannya di dapatkan dri banyak sumber seperti buku, jurnal, artikel dan lainnya. Menurut Bogdan \& Biklen, S (1992) menyatakan bahwa penelitian kualitatif adalah prosedur yang menghasilkan data deskriptif berupa kaitannya terhadap orang-orang tertentu, sedangkan menurut menurut Sugiyono (2010) kualitatif ialah metode yang berlandas pada filsafat positivme, digunakan untuk meneliti kondisi objek yang alamiah sebagai lawannya eskperimen, dimana peneliti melakukan pengambilan sampel bersumber data. Jadi dari adanya pengertian-pengertian di atas, dapat disimpulkan bahwa sumber teorinya diambil dari hasil studi kepustakaan yang terdapat di beberapa referensi.

\section{Hasil dan Pembahasan}

\section{A. Perilaku Generasi Milenial}

Perilaku merupakan hasil dari semua pengalaman dan interaksi manusia dengan lingkungannya yang wujudnya yaitu pengetahuan, sikap, serta tindakan. Perilaku adalah respon atau reaksi seorang individu terhadap stimulus luas ataupun dari dirinya sendiri (Notoatmojo, 2010) Perilaku adalah segenap manifestasi hayati individu dalam berinteraksi dengan lingkungan, mulai dari perilaku yang Nampak maupun tidak Nampak, dari yang dirasakan sampai yang tidak di rasakan (Oktaviana, 2015).

Begitu juga dengan perilaku dari generasi milenial terhadap nilai-nilai pancasila. Di era yang serba maju atau teknologi ini masih banyak individu yang salah dalam menyikapi nilai pancasila jika dilihat dari perilakunya. Masih banyak tindakan-tindakan menyimpang yang seolah mengapus nilai pancasila yang ada.

Dilihat dari sila pertama "Ketuhanan yang Maha Esa" Saat ini masih banyak sekali masyarakat dari warga negaranya yang kurang dalam menjalankan kewajiban beragamanya. Jika dicontohkan saat adzan berkumandang, bukannya mereka yang sedang berkumpul untuk segera pergi ke masjid tetapi mereka tetap melanjutkan pembahasannya tanpa memperdulikan seruan adzan tersebut.

Pada sila kedua "Kemanusiaan Yang Adil dan Beradap". Ketika kumpul bersama di suatu tempat, cenderung memperlihatkan sikap individual. Masing- 
masing orang hanya terfokus pada ponselnya, tidak perduli pada orang lain dan lingkungan sekitar.

Pada sila ketiga " Persatuan Indonesia”. Pada sila ini seharusnya masyarakat saling bahu membau menciptakan Negara yang rukun dan sehat, tetapi masih banyak perseteruan antar warga negaranya yang hanya perduli dengan dengan dirinya sendiri dan mau menang sendiri.

Pada sila keempat "Kerakyatan yang Dipimpin Oleh Hikmat Kebijaksanaan Dalam Permusyawaratan Perwakilan". Contoh perilakunya adalah masih banyak yang kurang menghargai pendapat orang lain, ketika dalam sebuah diskusi karena menurutnya hanya pendapatnya yang benar dan menolak pendapat orang lain, krang berpartisipasi saaat ada rapat organisasi,dan memaksa pilihan orang lain saat dalam pemilihan umum.

Pada sila kelima yaitu "Keadilan Sosial Bagi seluruh Rakyat Indonesia". Banyak sikap yang dari nilai pancasila kelima ini yang tidak di terapkan. Seperti contoh pilih-pilih dalam pertemanan, pilih kasih dalam pergaulan dan lainnya. Adapun sikap gotong royong yang mulai pudar, banyak yang melanggar lalu lintas, buang sampah sembarangan dan masih banyak lagi.

Dari kelima sila yang sudah di jelaskan diatas, dapat terlihat jelas bahwasanya masih banyak perilaku masyarakat khususnya generasi milenial yang kurang menerapkan dalam kehidupan sehari-hari. Maka dari itu diperlukan cara serta upaya untuk menanamkan nilai pancasila di zaman yang serba teknologi dan modern.

\section{B. Hubungan Nilai Pancasila Diera Milenial}

"Lima unsur yang terdapat pada pancasila bukanlah hal yang baru pada pembentukan Negara Indonesia, teatapi sebelumnya dan selama-lamanya telah dimiliki oleh rakyat bangsa indonesia yang nyata ada dan hidup dalam jiwa masyarakat Prof. DR. Drs, Notonegoro, SH (1967). Begitupun dari segi filsafat Negara bahwasanya pancasila sebagai dasar Negara filsafat Negara. Manusia sebagai pendukung pokok sila-sila pancasila secara antologis memiliki hal yang mutlak, yaitu susunan kodrat, raga dan jiwa, jasmani dan rohani, kodratnya sebagaib makhluk sosial, sebagai makhluk tuhan maka secara hirarki sila pertama ketuhanan yang maha esa mendasari dan menjiwai keempat sila lainya. (Notonegoro 1975) 1 Juni 2017, Presiden Joko Widodo berkata "Pancasila merupakan hasil satu kesatuan proses yang dimulai dengan rumusan pancasila 1 Juni 1945 yang di pidatokan oleh Ir.Soekarno, Piagam Jakarta 22 Juni 1945, dan rumusan final pancasila 18 Agustus 1945 adalah jiwa besar para ulama dan pejuang kemerdekaan daris eluruh pelosok nusantara sehingga kita bisa membangun kesepakatan bangsa yang mempersatukan kita".

Bangsa Indonesia adalah bangsa yang punya segenap potensi, dan juga merupakan bangsa yang amabesar dan kaya. Bangsa yang punya kentungan karena lokasinya yang strategis diantara jalur distribusi barang serta jasa internasional, sudah pasti memiliki sumber daya yang melimpah danjuga sumber energinya yang seolah tidak akan habis, Karena hal-hal tersebut maka Indonesia sangat rentan kehancurannya, Indonesia banyak berbeda dalam segala bidang dari bangsa lain. 
Oleh sebeb itu, amat sangat disayangkan bila sejarah Indonesia yang sudah tumbuh begitu lamanya hancur karena adanya perebutan kekuasaan oleh kelompok yang serakah. Perpecahan tersebut sangat tidak diingin kan oleh bangsa Indonesia. Diperlukan adanya rasa tanggung jawab pada seluruh warganya, tentunya juga pada generasi penerus khususnya generasi milenial. Generasi yang mempunyai usia produktif antara 18-36 tahun, yang merupakan usia generasi produktif.

Generasi yang mempunyai peran penting untuk keberhasilan bangsa dan Negara. Namun, kehidupan di era yang serba teknologi dan otomatis ini cenderung menjadi pribadi yang sangat mudah di pengaruhi hal dari luar. Hal tersebut merupakan titik kritis bagi pada penerus masa depan. Makanya generasi ini diharapkan tidak melupakan nilai luhur yang ada pada pancasila seperti semangat bersatu, saling gotong royong, percaya pada diri sendiri dan sebagainya.

Pancasila pada hakikatnya harus dipelihara dan diamalkan. Generasi milenial harus berada di titik terdepan, memengang teguh nilai pancasila untuk mencegah hal yang bertentangan dari pancasila. Karena bahwaasanya jalan bangsa ini juga ada ditangan generasi penerus seperti generasi milenial ini.

\section{Upaya Menanamkan Nilai Pancasila Pada Generasi Milenial}

Pancasila merupakan dasar falsafah dari Negara Indonesia dan ideologinya diharapkan menjadi pandangan hidup bangsa Indonesia. Sehingga dasar dari pemersatu, lambang pemersatu, dan kesatuan bagian pertahanan bangsa dan Negara. Nilai dari pancasila merupakan nilai filsafat yang mendasar dan dijadikan dasar dari norma yang ada di Indonesia. Hal ini berarti bahwa semua peraturan yang ada di Indonesia itu bersumber dari pancasila.

Pancasila berisi seperangkat nilai dasar yang ideal, juga merupakan komitmen kebangsaan, identitas dari bangsa, dan menjadi dasar dari adanya pembangun karakter di Indonesia.

Pancasila disuarakan oleh para pendiri bangsa Indonesia agar bangsa mempunyai sebuah pondasi yang kuat dalam menjalankan adanya pemerintahan. Berarti, dari adanya pancasila maka Indonesia mempunyai dasar dan ponasi yang kuat dalam bernegara agar tidak dapat dipengaruhi serta dijajah oleh Negara lain.

Pancasila merupakan ideologi yang mempunyai wewenang dan terdapat fungsi utama ialah sebagai cita-cita atau tujuan yang harus dicapai secara bersama, kedua sebagai pemersatu dikata terdapat konflik sehingga dapat menemukan solusi, dan dalam pernyataan fungsi ideologi tujuan masyarakat adalah mencapai tujuan dari ideologi itu sendiri. Adapun para tokoh yang mengemukakan pendapatnya terkait pancasila.

Yang pertama ada Ir.Soekrano yang berkata Pancasila adalah isi dalam jiwa bangsa Indonesia yang turun-temurun lamanya terpendam bisu oleh kebudayaan barat. Dengan demikian, Pancasila tidak saja falsafah negara, tetapi lebih luas lagi, yakni falsafah bangsa Indonesia.

Yang kedua Muh.Yamin yang berkata Pancasila berasal dari kata panca yang berarti "lima" dan sila berarti "sendi, atas, dasar atau peraturan tingkah laku yang penting serta baik". Dengan demikian Pancasila merupakan lima dasar yang berisi pedoman atau aturan tingkah laku yang penting dan baik. 
Dan yang terakhir Notonegoro yaitu berkata Pancasila adalah dasar falsafah dari negara Indonesia, sehingga dapat diambil kesimpulan bahwasanya Pancasila adalah dasar falsafah serta ideologi negara yang dapat diharapkan menjadi pandangan hidup bangsa Indonesia sebagai dasar kesatuan.

Dari beberapa tokoh tersebut, seharusnya kita sebagai generasi penerus harus bisa menerapkan nilai-nilai pancasila dalam kehidupan sehari-hari. Sudah seharusnya kita menghargai jasa dari pahlawan yang sudah berhasil merumuskan dasar Negara sebagai pedoman hidup. Karena seperti yang kita ketahui bahwa perjuangan hingga mencapain titik saat ini sangatlah berat, tetapi para pahlawan tidak dengan mudah menyerah dan putus asa.

Seiring dengan adanya perkembangan IPTEK yang semakin maju dan modern masuk ke Indonesia mengakibatkan lunturnya nilai nasionalisme dan patriotisme khususnya kalangan muda zaman milenial ini. Jiwa pancalila yang lunturpun jadi pengaruh buruk bagi bangsa Indonesia.

Maka dari itu, diperlukan adanya penegasan kembali dserta mengembalikan kedudukan pancasila sebagai dasar Negara, ini merupakan hal yang penting karena sudah banyak kesalahan tentang penafsiran pancasila. Penafsiran itu menyatakan bahwa Pancasila bukan hanya sebagai dasar negara tetapi Pancasila sebagai alat kekuasaan yang dapat mengendalikan semua apapun yang dilakukan negara Indonesia. Yakni mengandung pengertian bahwa nilai-nilai Pancasila merupakan pegangan dalam mengatur sikap dan tingkah laku yang menjadi pedoman. Bangsa Indonesia harus menghayati dan mengamalkan nilai-nilai kebenarannya.

Rajasa (2007), menyatakan bahwa generasi muda harus mengambangkan karakter nasionalisme melalui tiga proses yaitu yang pertama dengan pembangun karakter atau character builder generasi muda berperan membangun karakter positif bangasa melalui kemauan keras, untuk menjunjung nilai-nilai moral serta menginternalisasikannya pada kehidupan nyata. Kedua adalah pemberdaya karakter atau character enabler generasi muda menjadi role model dari pengembangan karakter bangsa yang positif, dengan berinisiatif membangun kesadaran kolektif dengan kohesivitas tinggi, misalnya menyerukan penyelesaian konflik. Dan yang terakhir adalah perekayasa karakter atau charcter engineer yaitu generasi muda berperan dan berprestasi dalam ilmu pengetahuan dan kebudayaan, serta terlibat dalam proses pembelajaran dalam pengembangan karakter positif banmgsa sesuai dengan perkembangan zaman (Ginting, 2017).

Adapun upaya-upaya untuk menanamkan nilai pancasila:

a. Mempunyai satu agama dan tekun terhadap agama tersebut, serta tidak memeksa orang lain untuk masuk ke agamanya.

b. Harus menanamkan jiwa menghargai perbedaan yang ada dari banyaknya suku,ras,agama. Dan menjaga adab, kesopanan.

c. Mencintai tanah air dan turut serta menjaga kesatuan bangsa.

d. Mengandalkan musyaearah mufakat untuk mencapai tujuan bersama.

e. Selalu membantu orang lain yang sedang susah, mengormati hasil musyawarah, serta memperjuangkan adanya keadilan.

Seiring berjalannya waktu nilai pancasila tidak ada yang berubah tetapi mulai luntur karena sikap yang kurang mencintai bangsanya diiringi dengan perkembangan IPTEK. Tetai sebagai generasi penerus harusnya tetap memfilter serta menyaring semua hal dari luar yang masuk ke dalam bangsanya. 
Jurnal Evaluasi dan Pembelajaran, 3 (1), Maret 2021 - 34

Angel Dwi Septianingrum, Dini Anggraeni Dewi

Pancasila yang merupakan buah penggalian dari perumusan dari apa yang pernah ada akan mandul jika tidak di interelasikan dalam kehidupan. Maka dari itu pancasila diharapkan benar menjadi watak dan pola ytang kontras mencerminkan cirri pribadi. Pancasila diharapkan menjadi cita-cita normative yangv memasuki tulang dan daging putraputri bangsa. (Karim, 2004: 36).

\section{Simpulan}

Pancasila dasar Negara yeng mempunyai makna dan nilai yang terkandung didalamnya sebagai pedoman hidup. Nilai pancasila juga merupakan nilai filsafat uang dijadikan aturan bagi norma di Indonesia. Pada zaman ini diperlukan adanya penegasan, penanaman nilai pancasila agar kedudukannya sebagai dasar Negara tidak hilang.

Maka dari itu penerapannya harus ada kapan pun dan dimanapun lingkungannya. Harus diajarkan di jenjang sekolah maupun perhuruan tinggi. Kita sebagai penerus bangsa harus menerapkan nilai pancasila di kehidupan sehati-hari, agar sejalan dengan nilai dan norma pancasila. Jangan juga sampai salah arah, kita harus menerapkan nilai serta norma tersebut juna mengahrgai jasa para pahlawan yang telah berjuang tanpa mengenal lelah dan putus asa.

\section{Daftar Pustaka}

Agus, A. A. (2016). Relevansi Pancasila Sebagai Ideologi Terbuka di Era Reformasi. Jurnal Office.

Anggriani, Fitri. (2018). Opini Mengenai Hilangnya Nilai Pancasila dalam Kehidupan Berbangsa dan Bernegara. Universitas Negeri Jakarta. Retrieved from https://www.researchgate.net/publication/330468779_Opini_Mengenai_Hilang nya _Nilai_Pancasila_dalam_Kehidupan_Berbangsa_dan_Bernegara

Bogdan, R. \& Biklen, S. (1992). Qualitative Research for Education. Bostin, MA: Allyn and Bacon

Damanhuri, D., et al., (2016). Implementasi Nilai-Nilai Pancasila Sebagai Upaya Pembangunan Karakter Bangsa. Untirta Civic Education Journal, 1(2).

Darmawan. (2018). Revitalisasi Pancasila Sebagai Pedoman Hidup Bermasyarakat di Era Globalisasi. Universitas Islam Negeri Raden Intan Lampung

Ginting, H. (2017). Peranan Pancasila Dalam Menumbuhkan Karakter Bangsa Pada Generasi Muda. In Prosiding Seminar Nasional Tahunan Fakultas Ilmu Sosial Universitas Negeri Medan (Vol. 1, pp. 197-201).

Karim, M. Abdul. (2004). Menggali Muatan Pancasila dalam Perspektif Islam. Yogyakarta: Surya Raya.

M. Taufik, dkk. (2018). Pendidikan Pancasila untuk Perguruan Tinggi. (S. Hayat, Ed.). Malang: Baskara Media.

Notoatmodjo, S. (2010). Metodologi Penelitian Kesehatan. Jakarta : Rineka Cipta.

Notonagoro. (1967). Beberapa Hal Mengenai Falsafah Pantjasila: Pengertian Inti-IsiMutlak Jakarta, Universitas Pantjasila.

Notonegoro. (1975). Pancasila Secara Ilmiah Populer. Jakarta: Pancuran Tujuh. 
Jurnal Evaluasi dan Pembelajaran, 3 (1), Maret 2021 - 35

Angel Dwi Septianingrum, Dini Anggraeni Dewi

Oktaviana. R. (2015). Hubungan antara kelompok teman sebaya dengan perilaku "X" Palembang. Jurnal Psyche, 9(1), 8-16.

Rajasa.(2007). Kongres Pancasila IV. Jakarta: Bumi Aksara.

Sugiyono. (2010). Metode Penelitian Kuantitatif Kualitatif dan $R n D$; Penerbit CV Alvabeta, Bandung.

Yudistira. (2016). Aktualisasi \& Implementasi Nilai-Nilai Pancasila dalam Menumbuhkan Kembangkan Karakter Bangsa. In Seminar Nasional Hukum (Vol. 2, pp. 421-436). 